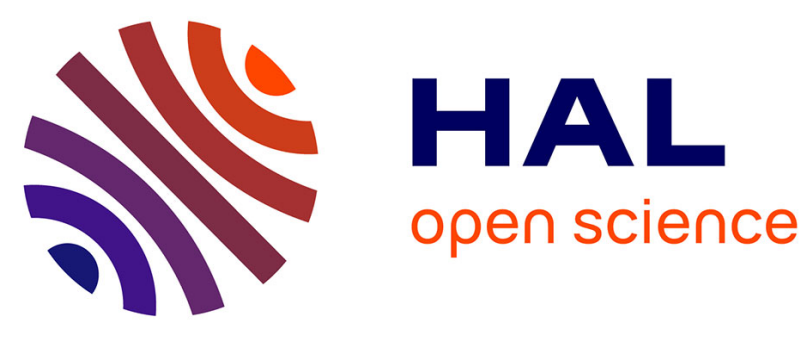

\title{
Negative-ion production on carbon materials in hydrogen plasma: influence of the carbon hybridization state and the hydrogen content on $\mathrm{H}$ - yield
}

Ahmad Ahmad, Cedric Pardanaud, Marcel Carrère, Jean-Marc Layet, Gilles

Cartry, Alix Gicquel, Pravin Kumar, David Eon, Cédric Jaoul, Richard Engeln

\section{To cite this version:}

Ahmad Ahmad, Cedric Pardanaud, Marcel Carrère, Jean-Marc Layet, Gilles Cartry, et al.. Negativeion production on carbon materials in hydrogen plasma: influence of the carbon hybridization state and the hydrogen content on H- yield. Journal of Physics D: Applied Physics, 2014, 47 (8), pp.085201. 10.1088/0022-3727/47/8/085201 . hal-00943265

\section{HAL Id: hal-00943265 https://hal.science/hal-00943265}

Submitted on 8 Apr 2014

HAL is a multi-disciplinary open access archive for the deposit and dissemination of scientific research documents, whether they are published or not. The documents may come from teaching and research institutions in France or abroad, or from public or private research centers.
L'archive ouverte pluridisciplinaire HAL, est destinée au dépôt et à la diffusion de documents scientifiques de niveau recherche, publiés ou non, émanant des établissements d'enseignement et de recherche français ou étrangers, des laboratoires publics ou privés. 


\title{
Negative-ion production on carbon materials in hydrogen plasma:
}

\section{Influence of the carbon hybridization state and the hydrogen content on $\mathrm{H}^{-}$yield}

\author{
Ahmad Ahmad, Cédric Pardanaud, Marcel Carrère, Jean-Marc Layet, and Gilles Cartry \\ Aix-Marseille Université, CNRS, PIIM, UMR 7345, 13013 Marseille, France \\ Alix Gicquel \\ LSPM, CNRS-UPR 3407 Université Paris 13, Avenue J. B. Clément, F-93430 Villetaneuse Labex \\ SEAM, PRES Sorbonne Paris Cité, France
}

Pravin Kumar

Inter University Accelerator Centre (IUAC), New Delhi 110067, India

David Eon

Institut Néel, CNRS and Université Joseph Fourier, BP166, 38042 Grenoble Cedex 9, France

Cédric Jaoul

Université de Limoges, CNRS, SPCTS UMR 7315, 12 rue Atlantis, 87068 Limoges, France

Richard Engeln

Department of Applied Physics, Eindhoven University of Technology, Eindhoven, The Netherlands

Key words: Negative-ions, hydrogen plasma, mass spectrometer, carbon materials, Negative-ion sources, Raman spectroscopy, diamond

PACS: 52.40.Hf, 52.40.Kh, 29.25.Ni, 52.27.Cm 


\begin{abstract}
Highly oriented poly crystalline graphite (HOPG), boron-doped diamond (BDD), nanocrystalline diamond (NCD), ultra-nano-crystalline diamond ( $\mathrm{NCD}$ ), fullerenes C60 and C70 and Diamond Like Carbon (DLC) surfaces are exposed to low pressure hydrogen plasma in a $13.56 \mathrm{MHz}$ plasma reactor. Relative yields of surface produced $\mathrm{H}^{-}$ions due to bombardment of positive ions from the plasma are measured by an energy analyzer cum quadrupole mass spectrometer. Irrespective of plasma conditions (0.2 and $2 \mathrm{~Pa}), \mathrm{HOPG}$ surfaces show the highest yield at room temperature (RT), while at high temperature (HT), the highest yield ( 5 times compared to HOPG surface at room temperature) is observed on BDD surfaces. The shapes of ion distribution functions (IDFs) are compared at RT and HT to demonstrate the mechanism of ion generation at the surface. Raman spectroscopy analyses of the plasma exposed samples reveal surface modifications influencing $\mathrm{H}^{-}$ production yields, while further analyses strongly suggest that the hydrogen content of the material and the $\mathrm{sp} 3 / \mathrm{sp} 2$ ratio are the key parameters in driving surface ionization efficiency of carbon materials under the chosen plasma conditions.
\end{abstract}




\section{I- Introduction}

Due to certain advantages over positive ion beams, negative ion beams are widely used in special fields of science. For example, negative ion sources are used to double the energy in electrostatic accelerators by stripping excess electrons and re-accelerating the positive ions thus formed ${ }^{1}$. Multicathode source of negative ion by cesium sputtering (MC-SNICS) based tandem accelerators are being used extensively for accelerator based mass spectrometry (AMS) ${ }^{2}$. Recently, it has been proposed to use both positive and negative-ion beams in space propulsion thrusters ${ }^{3,4}$, instead of positive ion beams alone to reduce neutralization issues. Negative-ion sources are also of interest for microelectronics applications $5,6,7,8,9$. Highly selective, highly anisotropic, notch-free and charge-build-up damage-free etching was evidenced on semiconductors using negative ion beams ${ }^{10,11,12}$. Special merits of negative ion beams have been recognized in context of future fusion technology such as International Thermonuclear Experimental Reactor (ITER) ${ }^{13,14,15}$ and there is enough scope for the growth of this field. For efficient heating of fusion plasma, the neutral beam injector (NBI) system of ITER will require $1 \mathrm{MeV} \mathrm{H}^{-} / \mathrm{D}^{-}$beam of $\sim 40 \mathrm{~A}_{\text {current }}{ }^{16,17}$. Here, negative ion beam has been chosen due to much higher neutralization efficiency at high energy in comparison of positive ion beam.

Negative ions in plasmas are mainly produced on surfaces by sputtering of target materials or backscattering of incoming particles (Surface Plasma Sources ${ }^{18}$ ), or in the plasma volume by dissociative electron attachment on vibrationally excited molecules (Volume Sources ${ }^{19,20,21,22,23}$ ). The production on the surfaces of low work-function materials, such as Cs, is widely used for achieving excellent negative-ion yields ${ }^{24,25,26,27,28,29}$. However, in context of a fusion reactor, inherent problems associated with Cs such as diffusion in the accelerator stage of NBI system, breakdowns, contaminated discharges... demand the development of cesium-free negative-ion sources. Therefore, understanding the complex Cs-free plasma-surface interaction is of great significance so that desired material properties can be tailored and optimized for enhanced $\mathrm{H}^{-}$yields and development of cesium-free 
negative-ion sources. Furthermore, a key challenge for fusion power is controlling heat transport at the boundary between the hot plasma core $\left(>10^{6} \mathrm{~K}\right)$ and the low temperature $\left(3.10^{2}-10^{3} \mathrm{~K}\right)$ walls. Because of excellent mechanical and thermal properties, carbon-fibers-components (CFC), which are made of graphite ${ }^{30}$, have been used in many tokamaks as divertor or limiter (exhaust region) tiles, and may be used in the first phase of operation of the ITER project ${ }^{31}$. Because of outstanding mechanical and thermal properties, diamond is also envisaged as a divertor material. Its behavior under highdensity plasma exposure has been studied, whether in tokamaks or in high-flux experiments specially designed for plasma-surface interaction investigations ${ }^{32,33,34,35,36,37,38,39}$. Negative ion production on materials can affect the heat load received by the divertor through the $\mathrm{H}^{-} / \mathrm{H}^{+}$reaction of neutralization and consequent radiation ${ }^{40}$. Thus, formation of negative ions on carbon surfaces must be taken into account for understanding and modeling of the divertor heat load.

In earlier publications, we have already demonstrated that enough $\mathrm{H}^{-}$yield is produced on $\mathrm{HOPG}$ surface exposed to $\mathrm{H}_{2} / \mathrm{D}_{2}$ plasma ${ }^{41,42,43}$. Further, in comparison to the yield on HOPG surface at RT, about 5 times enhancement has been observed on BDD surface at HT $\left(400^{0} \mathrm{C}\right)^{44}$. Furthermore high yields of $\mathrm{H}^{-}$negative-ions have already been observed in beam experiments using different kinds of carbon material (HOPG, DLC...) $)^{45,46,47,48,49,50,51}$. Therefore, with the aim of developing cesium-free negative-ion sources as well as understanding the complex plasma-surface interaction in tokamaks, production of negative ions on carbon materials exposed to hydrogen plasmas deserve for a detailed study. The objective of the present paper is to compare relative yields of negative ions produced on the surfaces of various carbon materials and to correlate yields with surface properties using Raman analysis. Highly oriented poly crystalline graphite (HOPG), boron-doped diamond (BDD), nanocrystalline diamond (NCD) ultra-nano-crystalline diamond (uNCD),fullerenes C60 and C70 and Diamond Like Carbon (DLC) surfaces have been chosen for yield measurements. 


\section{II- Experiment}

Experiments were performed in a helicon reactor which consists of a source chamber and a diffusion chamber. The $13.56 \mathrm{MHz}$ power supply is used to form low-pressure hydrogen plasma in the source chamber. Plasma is then allowed to diffuse vertically down into the diffusion chamber, where plasma surface interactions take place. All measurements were performed in the diffusion chamber. With the help of a special sample holder, negatively biased samples are placed into the diffusion chamber. A precise control on angular (rotation of y-z plane around y axis) and linear movement (in y direction) of the sample is possible. There are provisions of biasing (up to $1 \mathrm{kV}$ ), heating (up to $800^{\circ} \mathrm{C}$ ) and cooling (at $\mathrm{LN}_{2}$ temperature) of sample surface. In front of sample (y-z plane) and $37 \mathrm{~mm}$ away (minimum possible distance in $\mathrm{x}$ direction), an energy analyzer cum quadrupole mass spectrometer (interfaced with PC) is placed to detect surface produced negative hydrogen ions. The base pressure in the reactor down to $10^{-7} \mathrm{mbar}$ is achieved using a high speed turbo molecular pump (4001/s) along with rotary pump. A dedicated gas feed system along with a flow controller and a capacitance gauge is used for pressure measurement and control in the reactor. Other details of experimental set up are published elsewhere ${ }^{52}$.

The sample placed in the diffusion chamber is negatively biased with respect to the plasma potential and it allows positive ions to be accelerated towards the sample surface. This ion bombardment on the surface leads to the production of negative ions. Surface-produced negative-ions are accelerated in backward direction and cross the sheath in front of the sample, the plasma region and the sheath in front of the spectrometer nozzle before their detection. Surface produced $\mathrm{H}^{-}$ion energy distribution functions (IDFs) (intensity versus energy), were recorded at two experimental conditions: condition 1- $\mathrm{H}_{2}$ gas pressure of $0.2 \mathrm{~Pa}$ and $\mathrm{RF}$ injected power of $100 \mathrm{~W}$; condition 2- $\mathrm{H}_{2}$ gas pressure of $2.0 \mathrm{~Pa}$ and $\mathrm{RF}$ injected power of $20 \mathrm{~W}$. Using mass spectrometer, the positive ion distribution functions (intensity versus energy of $\mathrm{H}^{+}, \mathrm{H}_{2}{ }^{+}$and $\mathrm{H}_{3}{ }^{+}$) are also analyzed to know the 
plasma population in terms of positive ions and the plasma potential. At $2 \mathrm{~Pa} \mathrm{H}_{2}$ pressure, the plasma is mainly populated with $\mathrm{H}_{3}{ }^{+}$ions $(\sim 90 \%)$ while at $0.2 \mathrm{~Pa} \mathrm{H}_{2}$ pressure, the density of $\mathrm{H}_{2}{ }^{+}$ions has a major contribution $(\sim 93 \%)$ in the plasma. The energy corresponding to peak intensity in positive ion distribution functions is a measure of the plasma potential. The as-measured plasma potential was always found in agreement with its value measured by a Langmuir probe placed in the diffusion chamber (Scientific System smart probe). Besides plasma potential, the Langmuir probe also provided information on the electron density and temperature.

The RF fluctuations of plasma potential arising due to capacitive coupling affect the IDFs significantly (see discussion in 52) which further make the measurements more complex to interpret. To minimize RF fluctuations, a mechanical grounded screen was placed horizontally approximately $5 \mathrm{~cm}$ above the sample (in between the source and the diffusion chamber) and low injected power were used. More details are given in 52. The screen was removed only for measurements on C60 and C70 materials.

For measurements, the sample was first placed in front of the spectrometer with its surface normal to the axis of the spectrometer. Then, the plasma was produced and the IDFs were recorded. After measuring yields (defined as the area below IDF curves) at room temperature (RT) with different bias voltages $\left(\mathrm{V}_{\mathrm{s}}\right)$ and plasma conditions, measurements were performed at high temperatures $(\mathrm{HT})$. Temperature of the sample was varied from ambient to $800^{\circ} \mathrm{C}$. In order to get rid of possible intensity fluctuations due to any reason throughout the experimental campaign, the ion intensity on HOPG surface was taken as reference and measured systematically before and after yield measurements on the surfaces of other materials. For intensity variation from reference value on HOPG surface (if seen), measured intensity on other surfaces were corrected accordingly. Ion extraction voltage $\left(\mathrm{V}_{\text {ext }}\right)$ was kept at $75 \mathrm{~V}$ and spectrometer entrance energy $\left(\mathrm{e} \times\left[\mathrm{V}_{\mathrm{ext}}+\mathrm{V}_{\mathrm{ref}}\right]-\mathrm{V}_{\mathrm{s}}\right)$ of the ions created at rest on the surface was $\sim 95 \mathrm{eV}$ ( $\mathrm{V}_{\text {ref }}$ is the reference voltage at which spectrometer assembly was floated). To 
keep constant the entrance energy $(\sim 95 \mathrm{eV})$ for each bias voltage $\left(\mathrm{V}_{\mathrm{s}}\right)$, a reference voltage $\mathrm{V}_{\text {ref }}$ was applied accordingly. The potential profile between sample and spectrometer is explained in Figure 1 of reference 42. With constant entrance energy, influence of transmission through the spectrometer on IDFs can be ignored. The sample bias voltage $\left(\mathrm{V}_{\mathrm{s}}\right)$ and the plasma potential $\left(\mathrm{V}_{\mathrm{p}}\right)$ determine the energy of positive ion bombardment $\left(\mathrm{E}_{0}=\mathrm{e} \times\left[\mathrm{V}_{\mathrm{p}}-\mathrm{V}_{\mathrm{s}}\right]\right)$. C70 and $\mathrm{C} 60$ materials are electrically insulating. The energy of positive ion was therefore equal to the difference between plasma potential and floating potential $(\sim 25 \mathrm{eV})$. For measurements on these materials, and to compensate the low energy of the positive ions, the screen was removed to increase slightly the positive ion flux ( factor 2).

HOPG material (12 mm x $12 \mathrm{~mm}$ x $2 \mathrm{~mm}$ ) was of ZYB type purchased from MaTeck GmbH Company. The density and electrical resistivity of HOPG were $2.265 \mathrm{gm} / \mathrm{cm}^{3}$ and $3.5 \times 10^{-5} \mathrm{ohm}-\mathrm{cm}$ respectively.

Polycrystalline boron-doped diamond films were deposited at LSPM laboratory by plasma assisted chemical vapor deposition in a bell jar reactor (PLASSYS BJS 150) operating with a mixture of $\mathrm{H}_{2}, \mathrm{CH}_{4}$ and $\mathrm{B}_{2} \mathrm{H}_{6}$ gases. ${ }^{53}$ The (Boron/Carbon) ratio in the gas phase (defined as $2 \times\left[\mathrm{B}_{2} \mathrm{H}_{6}\right] /\left[\mathrm{CH}_{4}\right]$ ) and the methane concentration was set to $1000 \mathrm{ppm}$ and $4 \%$ respectively. The reactor was operated at $200 \mathrm{mbar}$ pressure and the injected microwave power was set to $3 \mathrm{~kW}$. The film was deposited on a $<100>$ oriented silicon substrate. The deposited doped diamond layer had a thickness of $3 \mu \mathrm{m}$ (determined by the weight gain of the substrate). The charge carrier density was estimated to be $1.5 \times 10^{21} \mathrm{~cm}^{-3}$ which leads to good electrical conductivity for biasing of the diamond layer. A SEM image of the BDD surface is shown in Figure 1.

Nano-crystalline diamond (NCD) and ultra-nano crystalline diamond ( $\mathrm{UNCD}$ ) layers were deposited at Institut Néel on $\langle 100\rangle$ oriented silicon substrate. Diamond nucleation and growth were done in a 5200 Seki technotron MPCVD reactor using the Bias Enhanced Nucleation method. A - 
$260 \mathrm{~V}$ bias voltage was applied on the substrate heated at $700^{\circ} \mathrm{C}$ during 7 min before growth. The diamond was grown at $900^{\circ} \mathrm{C}, 30$ Torr with a methane concentration of $1 \%$ in $\mathrm{H}_{2}$. Films obtained show grain size around $100 \mathrm{~nm}$ for NCD or $10 \mathrm{~nm}$ for uNCD with preferentially <111> family crystal plans.

The fullerene films were deposited on $\mathrm{Si}(110)$ substrates using the resistive heating method. The pellets were made from fullerene powder ( 99\% pure) by applying suitable pressure. The deposition was performed in a vacuum chamber by sublimation of a fullerene pellet at a rate of $\sim 1.0$ $\mathrm{nm} / \mathrm{sec}$ and by passing a current of $170 \mathrm{~A}$ in a tungsten boat. Since fullerene cage size is 6-7 Angstrom, it is not possible to observe microstructure of fullerene even with a high resolution SEM or TEM. Fullerene layers are insulating and cannot be biased. Therefore only yield measurements at floating potential are presented for these surfaces. Fullerene shape was expected to lead to more adsorbed hydrogen on the surface and consequently more hydrogen sputtering, which is the main mechanism of negative ion generation on the surface ${ }^{18}$. However, the fullerene is not at all suitable for fusion technology as wall material due to low melting point and poor thermal stability.

Hydrogenated amorphous carbon (a-C:H) films were deposited onto AISI M2 polished flat samples by plasma enhanced chemical vapor deposition technique (PECVD) using an industrial R\&D scale reactor (SULZER Sorevi, Limoges, France). The obtained Diamond Like Carbon (DLC) layers were around $1.5 \mu \mathrm{m}$ in thickness. Two different DLC materials, initially deposited and characterized for their tribological properties ${ }^{54}$, have been studied. DLC-b is deposited with more energetic ions than DLC-a leading to several differences between the two films. The first one (DLC-a) has a density of $1.6 \mathrm{~g} / \mathrm{cm}^{3}, 32 \%$ at. of hydrogen, a hardness $32 \mathrm{GPa}$ and the second one (DLC-b) a density of 2 $\mathrm{g} / \mathrm{cm}^{3}, 29 \%$ at. of hydrogen, a hardness $38 \mathrm{GPa}$. With greater hardness and density, DLC-b is supposed to have a sp3/sp2 ratio higher than DLC-a. AFM pictures of both surfaces are given onFigure 1. The surface morphology was imposed by a cristallised columnar titanium nitride sublayer used to 
improve adhesion between the steel sample and the a-C:H film. A slight difference in roughness (Sa $=8 \mathrm{~nm}$ for DLC-b and $\mathrm{Sa}=10 \mathrm{~nm}$ for DLC-a) could be due to the higher energy of ions that penetrate beneath the surface in accordance with the subplantation model ${ }^{55}$.

All samples have been analyzed by Raman microscopy performed in air at room temperature on pristine and bombarded surfaces using a Horiba-Jobin-Yvon HR LabRAM apparatus $\left(\lambda_{\mathrm{L}}=514.5\right.$ $\mathrm{nm}$ with a x100 objective). The laser power was kept below $\sim 1 \mathrm{~mW} / \mu \mathrm{m}^{2}$ to prevent material damages.

\section{III- A brief summary of previous research work:}

Extensive work has been done on surface production of negative ions in Cs-free plasmas using $\mathrm{HOPG}^{41,42,43,44,52,56}$. The analysis of the surface produced negative ion energy distribution functions (NIDFs) measured by the spectrometer confirmed two production mechanisms. Negative ions detected at high energy (tail of the NIDF) are produced on the surface by backscattering of positive ions $^{42}$. The variation in the energy tail of the NIDF in the plasma having different populations of positive ions is fully explained by the backscattering mechanism ${ }^{42}$ considering fragmentation of molecular ions at surface and sharing of energy. $\mathrm{In}_{2}{ }^{+}$dominated plasma, the maximum energy of the surface-produced negative ions is $\mathrm{E}_{0} / 2$ where $\mathrm{E}_{0}$ is the $\mathrm{H}_{2}{ }^{+}$impact energy and $\mathrm{E}_{0} / 2$ is the impact energy per nucleon. However, in $\mathrm{H}_{3}{ }^{+}$dominated plasma, the maximum energy of the surface-produced negative ions is $\mathrm{E}_{0} / 3$ where $\mathrm{E}_{0}$ is the $\mathrm{H}_{3}{ }^{+}$impact energy and $\mathrm{E}_{0} / 3$ is the energy per nucleon. It has been further shown that the main peak of the NIDF located at low energy corresponds to negative-ion created by the backscattering mechanisms and by the sputtering of adsorbed hydrogen atoms ${ }^{41,43}$. The global shape of the NIDF results from the production by backscattering and sputtering mechanisms ${ }^{52}$. This production occurs within the range of the positive ion penetration depth (few nanometers in the present experimental conditions). The hydrogen content of the carbon material within this range will be named "sub-surface hydrogen content" hereafter. 
At RT and with increasing positive ion energy (sample is biased with different negative voltage for this purpose), $\mathrm{H}^{-}$yield increases first and then decreases ${ }^{19}$. The decrease in yield at higher energy is thought to be due to negative-ion collection issues by the mass spectrometer and is not of major scientific interest ${ }^{56}$. In a recent paper ${ }^{44}$, we reported enhanced $\mathrm{H}^{-}$yield on BDD surface at $400^{\circ} \mathrm{C}$. At $400^{\circ} \mathrm{C}$, the negative-ion signal was maximum on BDD and was five times higher than $\mathrm{HOPG}$ at room temperature. Raman spectroscopy measurements carried out after experiments at high temperature showed that the BDD surface, modified by the plasma irradiation at room temperature, was progressively recovering a high $\mathrm{sp} 3 / \mathrm{sp} 2$ ratio when rising up the temperature. As hydrogenateddiamond is known to be a good electron emitter, the increase of the sp3/sp2 ratio of the bombarded layer with temperature could explain the increase of the negative-ion yield. These results were promising for the development of efficient Cs-free negative-ion sources.

The aim of the present paper is to extend these previous experiments to other plasma conditions and different carbon materials. Two plasma conditions (condition 1, $0.2 \mathrm{~Pa} \mathrm{H}_{2}$ pressure @ $100 \mathrm{~W}$ and condition 2, 2.0 $\mathrm{Pa} \mathrm{H}$ pressure @ $20 \mathrm{~W}$ ) and several materials (nano-crystalline diamond (NCD), ultra-nano crystalline diamond (uNCD), fullerenes C60 and C70 and Diamond Like Carbons (DLC)) have been chosen for experiments.

\section{IV- Results and Discussion}

The temporal evolution of yields on different surfaces at plasma condition 1 (0.2 Pa, RT measurements) is shown in Figure 2. Same measurements at plasma condition 2 (2 Pa) have already been published on BDD and HOPG surfaces ${ }^{44}$. The variations of yields with time are due to transient surface states created by plasma exposure, and possibly to outgasing of surface impurities because of surface-bombardment by positive ions. After $\sim 5$ minutes of plasma exposure, steady state is reached 
and almost constant yields are achieved. Yield measurements presented in the paper are on steady state surfaces. To get insight into the surface modifications by the plasma exposure, we performed Raman measurements of pristine and plasma exposed samples.

\section{a) Surface analyses}

Raman spectroscopy measurements on pristine and plasma exposed surfaces of HOPG and BDD are shown in Figure 3 (a) and 3 (b). These results have already been published ${ }^{44}$ for plasma condition $2(2 \mathrm{~Pa})$. For plasma condition $1(0.2 \mathrm{~Pa})$, similar surface modifications are observed. Contrary to pristine HOPG, which showed only a narrow $\mathrm{G}$ band located at $1580 \mathrm{~cm}^{-1}$, bombarded HOPG showed a broad G band, a D band located at $1350 \mathrm{~cm}^{-1}$ and a non-zero background between the $\mathrm{D}$ and $\mathrm{G}$ bands. These features were attributed to a decrease of aromatic domains' coherence length because of defects creation ${ }^{57,58,59}$. The Raman spectra of pristine BDD sample mainly showed a peak at $1332 \mathrm{~cm}^{-1}$ with an asymmetric profile (Fano profile of zone centre optical phonons ${ }^{60,61}$ ). After bombardment, appearance of a broad band at $1600 \mathrm{~cm}^{-1}$ (similar to bombarded HOPG) due to the presence of $\mathrm{sp}^{2} \mathrm{C}-\mathrm{C}$ bonds was seen ${ }^{62,63}$.The disappearance of the Fano profile at $1332 \mathrm{~cm}^{-1}$ suggested the presence of an underlying D-band. The presence of D band was confirmed by subtracting Raman signal on pristine surface from Raman signal on plasma exposed surface ${ }^{44}$.

Raman spectra of pristine NCD and uNCD surfaces are shown in Figure 3(c). These surfaces exhibit common features in the range of $520 \mathrm{~cm}^{-1}-980 \mathrm{~cm}^{-1}$ associated to the underlying silicon wafer. The NCD surface, which has lower grain size than BDD, shows a sharp diamond peak (at $\sim 1330 \mathrm{~cm}^{-}$ ${ }^{1}$ ) on top of a large band centered at $\sim 1350 \mathrm{~cm}^{-1}$. With further reduction in grain sizes (uNCD), this sharp diamond peak disappears, and only the peak $\sim 1350 \mathrm{~cm}^{-1}$ (D band) exists in the spectrum. Raman cross sections for sp2 carbon are known to be much higher (two orders of magnitude) than cross 
sections for sp3 carbon ${ }^{64}$. It probably explains the disappearance of the diamond peak on uNCD. For both materials, the broad bands centered at $\sim 1570-1600 \mathrm{~cm}^{-1}$ associated to non-zero background between peaks, showed amorphous phases and aromatic domains with short coherence length. Chow et $\mathrm{al}^{32}$, using a chemical vapor deposition (CVD) method, synthesized various diamond films of different grain size by controlling the $\mathrm{CH}_{4}$ concentration and the argon gas flow. They obtained similar Raman signatures. Figure 3(d) shows Raman spectra of NCD material after plasma exposure at different temperatures (for plasma condition 2), and similar trends are observed at plasma condition 1 $(0.2 \mathrm{~Pa}))$. For the sample exposed at room temperature, reduced intensity of the diamond peak at 1330 $\mathrm{cm}^{-1}$ and evolution of a broad band between $1400 \mathrm{~cm}^{-1}$ and $1525 \mathrm{~cm}^{-1}$ (between the $\mathrm{G}$ and $\mathrm{D}$ bands) are observed. Although these modifications are only minor compared to those observed on BDD surface, they are similar and indicate a loss of crystallinity and creation of defects accompanied by $\mathrm{sp}^{3}$ to $\mathrm{sp}^{2}$ conversion ${ }^{65,66}$. Raman measurements on $\mathrm{uNCD}$ surface after plasma exposure do not show any substantial change. It may be due to the fact that uNCD film thickness is the highest among all materials as evidenced by the reduced intensity of the Si peak in Raman measurement. Compared to unmodified bulk region, the modified surface contributes less to Raman signal. Figure 3(e) and 3(f) presents Raman spectra of plasma exposed DLC-a and DLC-b films at different temperatures. A linear background was systematically subtracted from the original spectra. The signal was then normalized to the G band intensity for comparison. DLC-a surface has not been heated to temperatures higher than $400^{\circ} \mathrm{C}$. Pristine spectrum shows a clear broad $\mathrm{G}$ band at $1540 \mathrm{~cm}^{-1}$ and a broad overlapped D band, typical for amorphous carbon ${ }^{63}$. In Raman spectra of DLC materials, photoluminescence (PL) background increases with $\mathrm{H}$ content due to hydrogen saturation of non-radiative recombination centres $^{67}$. The ratio between the slope of the linearly fitted background (in the $800-2000 \mathrm{~cm}^{-1}$ Raman shift range), and the G-band peak intensity can be used to estimate the $\mathrm{H}$ content when it is in the range of $15-45 \%{ }^{68,69}$. Also, it has been shown that the intensity ratio between $\mathrm{D}$ and $\mathrm{G}$ bands $\left(\mathrm{I}_{\mathrm{D}} / \mathrm{I}_{\mathrm{G}}\right)$ 
can be used to estimate $\mathrm{H}$ content in DLC materials in the range $0-30 \%$, with a better accuracy in the range $0-20 \%{ }^{69}$. Using the first method, the $\mathrm{H}$ content estimated for the pristine DLC-b material is 26 $\%$ which is quite close to $29 \%$ as measured by elastic recoil detection analysis (ERDA). The agreement with the measurement by ERDA is satisfactory considering uncertainty of the technique ${ }^{68}$. Raman spectra after plasma exposure at room temperature do not reveal any change of the hydrogen content._This is not surprising since the surface was already amorphous and hydrogenated before plasma exposure.

C60 and C70 materials have been analyzed using laser powers of $0.002 \mathrm{~W} / \mu \mathrm{m}^{2}, 0.02 \mathrm{~W} / \mu \mathrm{m}^{2}$, and $0.2 \mathrm{~W} / \mu \mathrm{m}^{2}$. The $\mathrm{C} 70$ spectra (not shown) are not influenced by the laser energy whereas the C60 spectra are. Under laser irradiation, the growth of the 113, 241 and $292 \mathrm{~cm}^{-1}$ bands, which are near the 118, 259 and $300 \mathrm{~cm}^{-1}$ bands described by Eklund et $\mathrm{al}^{70}$, is most probably due to photopolymerization of the C60 structures. It implies that low laser power and high integration times are needed to fully analyze C60 material. We observed no photo-polymerization of the C70 material, which is in agreement with results published elsewhere ${ }^{71}$. The cross section of photopolymerization is lower for $\mathrm{C} 70$ due to the reduction of reactive double bonds. A photoluminescence signal, one order of magnitude higher in intensity than the Raman signature, is detected for both C60 and C70 films. It is attributed to an electronic transition from the lowest unoccupied molecular orbital to the highest occupied molecular orbital. For isolated C60, this electronic transition is dipole forbidden but can exist in solids due to the Herzberg-Teller effect (vibronic mixing). Due to the fact that C60 and C70 films are insulators and were deposited on Si substrate, we could not biased these films effectively while exposing them to plasma for surface production of negative ions. Therefore, the positive ion energy (difference of plasma potential and floating potential) was too low $(\sim 25 \mathrm{eV})$ to create any subsurface modification that could have been observed by Raman measurements. As a consequence, we could not see any substantial changes on pristine and plasma exposed C60 and C70 films. 
Most of these measurements show that the surface of the different carbon materials are modified after plasma exposure, over a distance corresponding to the positive ion penetration range. The reader must therefore keep in mind that, despite the fact that we named the samples by their bulk composition, the sub-surface, where the negative-ions are created, is modified with respect to the pristine materials.

\section{b) Room temperature measurements}

For plasma condition $2(2 \mathrm{~Pa})$, the $\mathrm{H}^{-}$ion mean free path is of the order of the distance between the sample holder and the mass spectrometer $(\sim 37 \mathrm{~mm})$ leading to a loss of ions between emission and detection as explained in reference 44 and 52. The NIDFs have been measured at different sample to mass spectrometer distances. Corresponding relative intensities (area below NIDF) are represented in Figure 4(a). They are compared with a calculation of the $\mathrm{H}^{-}$intensity decrease due to electrondetachment collisions. Irrespective of ion energy, a cross section of $4.5510^{-20} \mathrm{~m}^{2}$ has been used for these calculations. This value corresponds to the detachment cross section of $75 \mathrm{eV} \mathrm{H}^{-}$ions colliding with $\mathrm{H}_{2}{ }^{72}$. At $100 \mathrm{eV}$, the cross section is $4.8510^{-20} \mathrm{~m}^{2}$. In the experiment, the energy of negative ions entering into the plasma lies in between 78 and $100 \mathrm{eV}$. Calculations and measurements are in good agreement. Slight difference at higher distances could be due to a misalignment of the mass spectrometer axis with the normal direction at the center of the sample. These results confirm that the loss of negative-ions under the present experimental conditions is mostly due to electron-detachment collisions with $\mathrm{H}_{2}$, and at $37 \mathrm{~mm}$ distance a $\sim 50 \%$ loss of intensity is expected. However, since yield measurements are relative, different materials can be compared irrespective of ion loss. Furthermore, as the detachment cross section is almost constant in the energy range considered, the shape of NIDF is not affected by the distance as shown in Figure 4(b). Unaffected shapes of NIDF with distance also demonstrate that the negative-ion detachment is the main $\mathrm{H}^{-}$collision process in the plasma at plasma 
condition $2(2 \mathrm{~Pa})$. We conclude that plasma condition $2(2 \mathrm{~Pa})$ is appropriate to compare different materials in terms of relative yields and shape of NIDF, despite the loss of negative ions. At plasma condition $1(0.2 \mathrm{~Pa})$, the mean free path is ten times higher and no loss of ions occurs between sample and mass spectrometer.

The NIDFs measured at plasma condition 1 and $2(0.2$ and $2 \mathrm{~Pa})$ for all chosen materials and at room temperature are shown in Figure 5. The tail of NIDFs is always in agreement with the maximum energy expected from the surface production of ions by the backscattering mechanism $\left(\mathrm{E}_{0} / 2\right.$ at plasma condition 1, $\mathrm{E}_{0} / 3$ at plasma condition 2, see paragraph III). Almost identical shapes of NIDFs demonstrate that negative-ions are produced on the surface of all materials by the same mechanisms, namely backscattering and sputtering. Furthermore, it also shows that the contribution of backscattering and sputtering to the total negative-ion surface production is almost the same for all materials ${ }^{52}$. Yields as a function of positive ion energy are represented in Figure 6 a) and c) for both plasma conditions and for all materials. Yield variations with positive ion energy are distorted by measurement issues when energy is increasing and are not of primary interest ${ }^{56}$. However, yield variations with material can be compared on these graphs. Since C60 and C70 films are insulators and cannot be biased, yields are measured at only one positive-ion energy $\left(\mathrm{E}_{0}=\mathrm{e} \times[\mathrm{Vp}-\mathrm{Vf}]\right.$, where $\mathrm{Vp}$ is the plasma potential and Vf the floating potential). Pristine DLC films are also insulating in nature but turned out to be conductive when exposed to hydrogen plasma. Despite the fact that the shapes of the NIDFs are almost similar on all surfaces, the intensities of NIDFs differ from one material to another. It was previously stated ${ }^{44}$ that BDD and HOPG surfaces present similar yields at condition 2 ( $2 \mathrm{~Pa}$ ) because plasma exposure leads to modifications in pristine surfaces resulting in similar final steady states of surfaces. This statement is not true since NCD, which presents evolution of its Raman signatures after plasma exposure similar to BDD, shows lower negative-ion intensity (see Figure 6 for different plasma conditions at RT and HT). The DLC surface shows $\sim 25 \%$ lower yields than the 
HOPG surface, which has been the best material so far for surface production of negative ions at room temperature. Yield differences on DLC-a and DLC-b surfaces are low (close to the experimental errors) and surprisingly are not correlated with the material density. At RT, yields of BDD, NCD and $\mathrm{uNCD}$ are lower than of HOPG, and the uNCD surface exhibits the lowest yields among all materials. Again no correlation with layer density can be made since diamond layers have the highest densities but not the highest yields. The C70 surface shows yieldw comparable to that of the HOPG surface. Surprisingly, the yield of the C70 surface is twice of that of the C60 surface.

\section{c) High temperature measurements}

For plasma condition $1(0.2 \mathrm{~Pa})$, NIDFs measured at a surface temperature of $400^{\circ} \mathrm{C}$ are shown in Figure 7 (a) and (c). Normalized NIDFs are also represented in Figure 7 (b) and (d) to demonstrate the contribution of each negative ion production mechanism to the total yield. The NIDFs obtained on BDD, NCD and uNCD surfaces are similar in shapes at $400^{\circ} \mathrm{C}$, and also similar to those obtained at $34^{\circ} \mathrm{C}$. It implies that negative ions are produced (irrespective of temperature conditions) on these surfaces by the same mechanisms (sputtering and backscattering) with similar contributions. This further suggests that hydrogen sub-surface content of diamond, which can lead to different sputtering and backscattering contributions to the total yield, does not change drastically with temperature in this range (this point will be discussed more in details in the following).

The shape of the NIDF measured on the HOPG surface at $400{ }^{\circ} \mathrm{C}$ is very different from the one measured at $34{ }^{\circ} \mathrm{C}$ (Figure 7 (b)). This difference is attributed to a decrease of the sputtering contribution due to a decrease of hydrogen sub-surface content ${ }^{41,43,44}$ (see also reference 52 for a modeling of the NIDF in the absence of hydrogen on surface).

Plasma exposure of DLC-b and DLC-a surfaces at $400{ }^{\circ} \mathrm{C}$ also leads to change (smaller compared to HOPG surface, see Figure 7 (d)) in the shape of NIDF. Sputtering contribution on DLC 
surfaces is probably decreasing but not as effectively as on HOPG surface. Higher yields on DLC-b surfaces than on HOPG surface (Figure 7 (c)) further suggests that H sub-surface content does not decrease as much as for HOPG. The H percentage in DLC films estimated from the Raman spectra (see paragraph "experiments") does not vary with temperature up to $600{ }^{\circ} \mathrm{C}$ and decreases to $14 \%$ at $700{ }^{\circ} \mathrm{C}$ (estimated with the ratio $\mathrm{I}_{\mathrm{D}} / \mathrm{I}_{\mathrm{G}}$ ). As Raman microscopy probes a few tens of nanometer of the film and negative-ions are created on the surface within the ion penetration depth (few nanometers in the present experiment), we can assume that the $\mathrm{H}$ content in the bulk remains unchanged at $400{ }^{\circ} \mathrm{C}$ whereas the $\mathrm{H}$ sub-surface content does change leading to a change in the shape of the NIDF.

Due to their poor thermal stability, experiments on C60 and C70 have not been performed at high temperature.

Yields versus positive ion energy plots at $400^{\circ} \mathrm{C}$ are shown in Figure 6 (b) and 6 (d) for both plasma conditions. At high temperature, yield on HOPG strongly decreases (factor of 3-6 depending on experimental conditions) and HOPG is no more the best negative-ion enhancer material. Yield on DLC-b material does not decrease at $400^{\circ} \mathrm{C}$ as much as observed for HOPG. This is correlated with a reduced decrease of the hydrogen content on this material. At high temperature, highest yields are obtained on diamond materials. Yields on diamonds at HT are even higher than yield on HOPG at RT. Indeed, it is observed an increase of the yield for all diamond materials when going from RT to $400^{\circ} \mathrm{C}$. Depending on experimental conditions the increase of the yield on diamond materials varies from $\sim 3-6$ times. At $400^{\circ} \mathrm{C} \mathrm{BDD}$ is the best negative-ion enhancer with a yield $\sim 5$ times higher than on HOPG surface at RT.

For plasma condition $1(0.2 \mathrm{~Pa})$, yield variations with temperature at positive ion energy of $100 \mathrm{eV}$ are shown in Figure 8. Similar results are obtained at other experimental conditions. From Figure 8, two kind of materials are identified, one in the which negative-ion yields are increasing with 
temperature (BDD, $\mathrm{NCD}$, uNCD) up to $400^{\circ} \mathrm{C}$, and another one in which the negative-ion yields are decreasing with temperature (DLC and HOPG). Analysis of NIDF shapes presented in Figure 5 and Figure 7 shows that the variations of the yields are always accompanied by a change of the shapes of NIDFs. When the yield is decreasing, the NIDF tails become relatively more important than the NIDF peak suggesting a decrease of the sputtering contribution due to a decrease of the hydrogen sub-surface content $^{52}$ (see for instance HOPG in Figure 7 (b), and DLC materials in Figure 5 (d) and Figure 7 (d), at RT and $400^{\circ} \mathrm{C}$ ). When the yield is increasing, NIDF tails become relatively less important than the NIDF peak suggesting an increase of the sputtering contribution due to an increase of the hydrogen sub-surface content ${ }^{52}$ (this is less obvious and requires a careful analysis of the data, however, it can be observed for diamond materials by comparing Figure 5 (c) and Figure 7 (b) at RT and $400^{\circ} \mathrm{C}$ ). Using the modeling presented in reference 52, it can be estimated that a variation of the hydrogen subsurface content in the range $0-40 \%$ leads to variations of the total negative-ion yield by a factor lower than 2. Higher decreases or increases in yields are observed in Figure 8. Therefore, changes in the sputtering contribution cannot explain alone the yield variations with temperature. We here assume that the yield variations are due to modifications of the electronic properties of the materials, consecutive to changes of the surface states with the temperature. Changes in the surface states, and consequences on negative-ion production are discussed hereafter.

\section{d) Discussion}

It was shown in reference 44 that at $\sim 800{ }^{0} \mathrm{C}$, plasma exposed $\mathrm{HOPG}$ surface is almost reconstructed (see also Figure 3(b) of the present paper). As shown by Raman spectrum (see Figure 3(f)), DLC surface is modified with increase in temperature. Indeed, the D band evolves in intensity and the $\mathrm{G}$ band shifts to higher values. These trends have been attributed to an increase of the aromatic domain size, and consequently to the decrease of the sp3 content ${ }^{73}$. Therefore, at high temperature both surfaces end up in a final state with enhanced $\mathrm{sp} 2$ content (lower sp3/sp2 ratio). In reference 44 
it was shown that exposing BDD samples to hydrogen plasma at high surface temperature results in a reduction of $\mathrm{sp} 2$ content (see also Figure 3(a) of the present paper) due to a preferential etching of $\mathrm{sp} 2$ phases $^{74}$. As seen in Figure 3(d), the NCD surface behaves in a similar fashion. With increasing temperature, the intensity of the band at $1330 \mathrm{~cm}^{-1}$, the characteristic of diamond materials, increases and the signal between the $\mathrm{G}$ and the $\mathrm{D}$ bands decreases. At $720^{\circ} \mathrm{C}$, the Raman spectrum is very similar to that obtained on pristine surface. Therefore the behavior of BDD surfaces with temperature can be generalized to other forms of diamond material. When increasing the temperature, the sp3/sp 2 ratio increases. The influence of the $\mathrm{sp} 3 / \mathrm{sp} 2$ ratio on yields is discussed in the following.

Most of hydrogenated doped and un-doped diamond faces ((111), (110), (100)) present negative electron affinity (NEA) while hydrogen-free diamond surfaces have positive electron affinity $(\mathrm{PEA})^{75,76,77}$. Negative electro-affinity is expected to favor negative-ion yield. Indeed, electron loss is almost suppressed on the outgoing trajectory of the negative-ion, since no unoccupied state is in resonance with the electron affinity level ${ }^{78}$. When increasing the temperature, diamond surfaces are progressively rebuilt. Appearance of NEA when temperature increases to $400^{\circ} \mathrm{C}$ could explain the higher surface ionization efficiency observed (higher yield). However, the decrease of the signal above $400^{\circ} \mathrm{C}$ is hard to understand since the exposed layer is still evolving towards a diamond layer, and should still present NEA. Furthermore, this explanation does not tell anything about yield decrease on graphite.

It has been shown that nano-diamond/carbon composite films can exhibit excellent field electron-emission properties ${ }^{79,80,81,82}$ depending on their sp3/sp2 ratio. Qualitatively speaking, a material releasing electrons easily in vacuum can be expected to be favorable for electron capture by incident particle. However, no direct correlation can be derived between field emission and negativeion surface production since these are two different mechanisms. A turn-on-field of only $\sim 2.5$ V/micro-meter has been measured for nano-diamond/carbon composite films ${ }^{80}$, which is about 8 times 
smaller than that of conventional microcrystalline diamond. The reasons for that are not clear. However, it is clear that the NEA property of diamond is not enough to obtain an efficient field emitter, the material must also present good electron conduction ${ }^{79,80}$. High sp2 content grains with proper alignment, grain boundaries and interconnection between grains are very crucial for electron conduction and to activate field emission ${ }^{79,80,81,82,}$. The maximum in yield at $400^{\circ} \mathrm{C}$ for diamond materials could be due to an optimized sp3/sp2 ratio and/or optimized grain boundaries. However, differences in the temperature of the maximum should be observed between diamond materials, since $\mathrm{sp} 3 / \mathrm{sp} 2$ ratios are not expected to be identical at a given temperature.

It has been previously explained that the hydrogen sub-surface content is varying when increasing the temperature. The model presented in reference 52 can be used to determine the hydrogen sub-surface content only if the NIDFs have been recorded in special experimental conditions where the sheath in front of the mass spectrometer is planar... Since the sheath was not planar in the present experiment, only tendencies in the variations of the hydrogen sub-surface content are discussed here, and no precise estimation of the hydrogen sub-surface content is given. Using Figure 5 (c) and Figure 7 (b) one can observe a slight change of the BDD NIDF shape between RT and HT. The main peak of the NIDF becomes relatively more important than the tail, suggesting an increase of the hydrogen sub-surface content between RT and $400^{\circ} \mathrm{C}$. Still from Figure 5 and Figure 7 , one can note that the hydrogen sub-surface content decreases on DLC materials and strongly decreases on graphite when temperature is increasing. As mentioned previously, variations of the sub-surface content in the range 0 to $40 \%$ lead to variation by a factor 2 of the negative-ion yield, under typical experimental conditions encountered here. Yield variations observed experimentally are much more important. Therefore it can be assumed that the hydrogen sub-surface content not only plays a role on the sputtering contribution, but also on the ionization efficiency by changing the electronic structure of the carbon material. It has already been observed in beam experiments that tetrahedral amorphous 
carbon (ta-C) surfaces present higher negative-ion yield when hydrogen terminated ${ }^{83}$. The increase of negative ion yields on diamond materials under the present experimental conditions could be due to a higher ionization efficiency due to the increase of hydrogen sub-surface content. The increase of the hydrogen content between $\mathrm{RT}$ and $400^{\circ} \mathrm{C}$ is probably resulting from the change of the sub-surface structure and the evolution of the $\mathrm{sp} 3 / \mathrm{sp} 2$ ratio. The decrease of yields could be related for all materials to a lower ionization efficiency due to a lower hydrogen content in the sub-surface. When the hydrogen sub-surface content decreases to almost zero (for instance graphite at $800^{\circ} \mathrm{C}$ ), the negativeion yield decreases to very low values. The decrease of the yield on diamond materials between 400 and $800^{\circ} \mathrm{C}$ is less pronounced than on $\mathrm{HOPG}$, most probably because of a limited decrease of the hydrogen sub-surface content. Hydrogen surface coverage of diamond is not expected to be affected by temperature below $\sim 1000^{\circ}{ }^{84}$. However, one must keep in mind that under the present experimental condition, the material in interaction with the plasma is modified by the ion bombardment and its properties are differing from the pristine material. Yamazaki ${ }^{85,86}$ studied hydrogen plasma and hydrogen ion-beam exposure of diamond surfaces. They showed that under exposure at room temperature an a-CH defective layer is formed on top of the diamond material. After annealing at $800^{\circ} \mathrm{C}$ under vacuum this defective layer is graphitized. Further exposure to plasma at $800^{\circ} \mathrm{C}$ leads to the etching of the graphitize layer and the diamond structure is retained after the treatment. Therefore, an increase of the hydrogen content of the "diamond" sub-surface till $400^{\circ} \mathrm{C}$ and a slight decrease above $400^{\circ} \mathrm{C}$ cannot to be excluded since the sub-surface is evolving from a defective a-CH layer to a diamond layer between RT and HT. Finally, the hydrogen sub-surface content is varying when the temperature is increasing, leading to changes of the surface electronic properties and to changes of surface ionization probabilities.

To conclude, a broad range of materials on the ternary phase diagram of bonding in amorphous carbon-hydrogen alloys ${ }^{87,88}$ have been studied by exposing different types of carbon layers to 
hydrogen plasmas at different surface temperatures. Some of them may have optimal properties to enhance surface ionization of hydrogen particles. Therefore it is highly probable that the ratio $\mathrm{sp} 3 / \mathrm{sp} 2$ and the hydrogen content are the key parameters influencing the negative-ion yield. In the present paper only trends have been given concerning variations of sp3/sp2 ratio and hydrogen content. It is planned for the future to go towards the determination of these parameters by the use of proper surface analyses. It is also planned to study the influence of other parameters such as the diamond doping. Indeed, despite all diamond materials behave similarly with temperature (yield increases up to $400^{\circ} \mathrm{C}$ and then decreases), the boron doped diamond (BDD) presents higher yields than the un-doped diamonds (NCD and uNCD).

\section{Conclusion:}

In this paper, we made a first attempt to compare and understand negative-ion surface production on several carbonaceous surfaces in hydrogen plasma. Highly oriented polycrystalline graphite (HOPG), boron-doped diamond (BDD), nano-crystalline diamond (NCD), ultra-nanocrystalline diamond (uNCD), fullerenes C60 and C70 and Diamond Like Carbon (DLC) samples have been chosen for the measurement of negative ion yields at two plasma conditions. At room temperature, the HOPG surface shows the highest yield among all carbon materials. Enhanced negative-ion yield on BDD surface ( 5 times of that on HOPG surface at low energy) is observed at $400^{\circ} \mathrm{C}$. Above $400^{\circ} \mathrm{C}$ yield on BDD decreases. Though yields on other diamond surfaces are lower than that on BDD surface, they show similar yield variations with temperature. Yields on DLC and HOPG materials are decreasing with surface temperature. The hydrogen sub-surface content and the $\mathrm{sp} 3 / \mathrm{sp} 2$ ratio of all the carbon materials seem to be the main parameters explaining the temperature variations of the negative-ion yield. Hydrogen sub-surface content and the sp3/sp2 ratio are influenced 
by the surface temperature of the plasma-exposed material. Raman measurements reveal surface modifications due to plasma exposure. Diamond materials (BDD, NCD) present an increasing sp3/sp2 ratio with temperature, whereas sp3/sp2 ratio is decreasing with temperature for DLC and HOPG materials.

The efficient production of $\mathrm{H}^{-}$ions on diamond surfaces is encouraging for the development of Cs-free negative ion source for fusion projects. For further understanding of negative ion production on carbon surfaces, measurements of electronic properties by UPS (Ultra-violet Photo-electron Spectroscopy) and hydrogen sub-surface content by TDS (Thermal Desorption Spectroscopy) are planned.

\section{Acknowledgement}

This work, supported by the European Communities under the contract of Association between EURATOM, CEA, and the French Research Federation for fusion studies, was carried out within the framework of the European Fusion Development Agreement. The views and opinions expressed herein do not necessarily reflect those of the European Commission. Financial support received from the French Research Agency (ANR) under grant ITER-NIS (08- BLAN-0047-05), grant CAMITER

(06-BLAN-0008-01). One of the authors (PK) is thankful to Department of Science and Technology (DST), India for providing financial assistance under BOYSCAST fellowship program. 

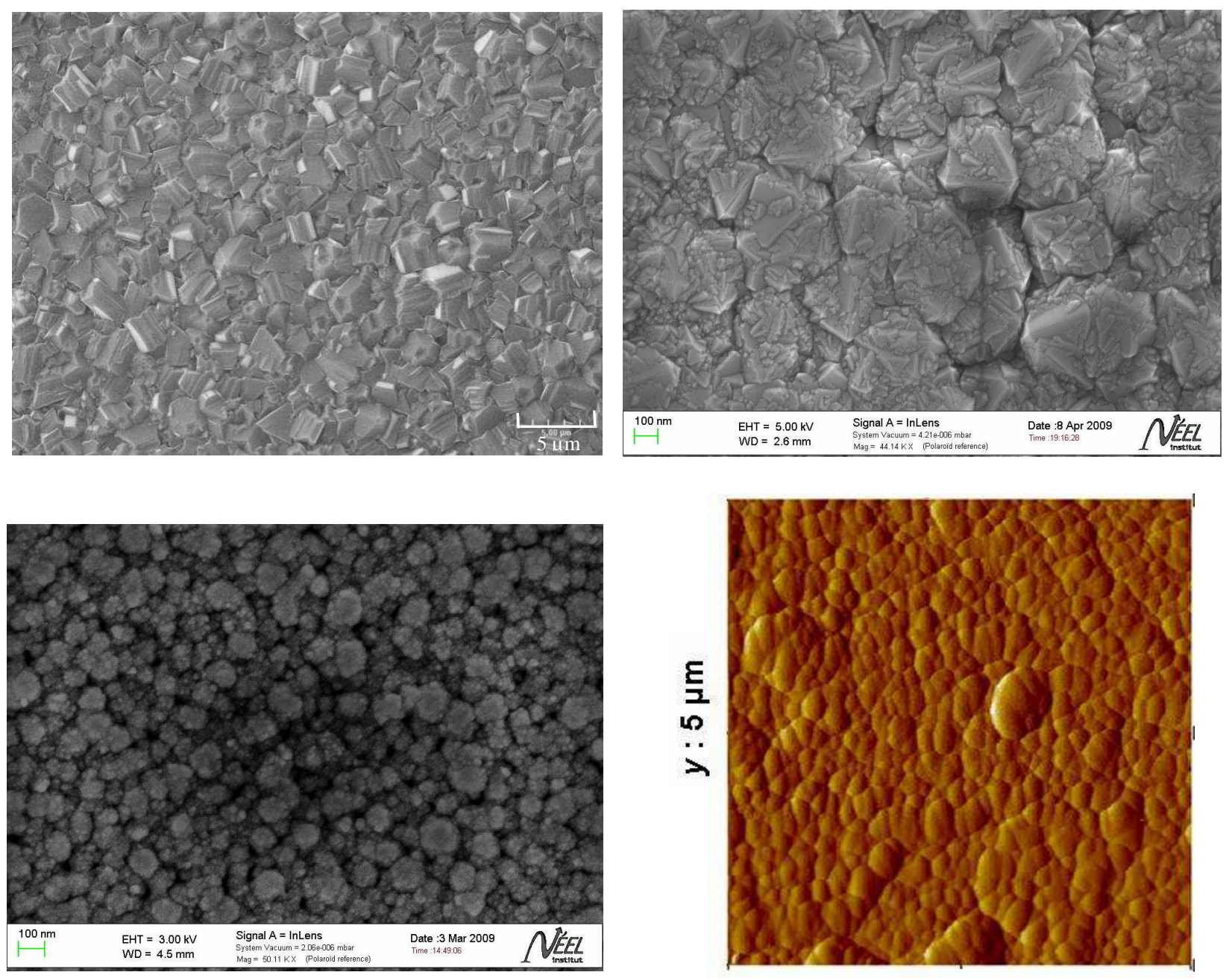

$x: 5 \mu \mathrm{m}$

Figure 1: left to right, top to bottom: SEM pictures of pristine boron Doped Diamond (BDD), nanocrystalline diamond (NCD), ultra nanocrystalline diamond (UNCD), and AFM picture of pristine diamond-like carbon layers (DLC-a) material. 

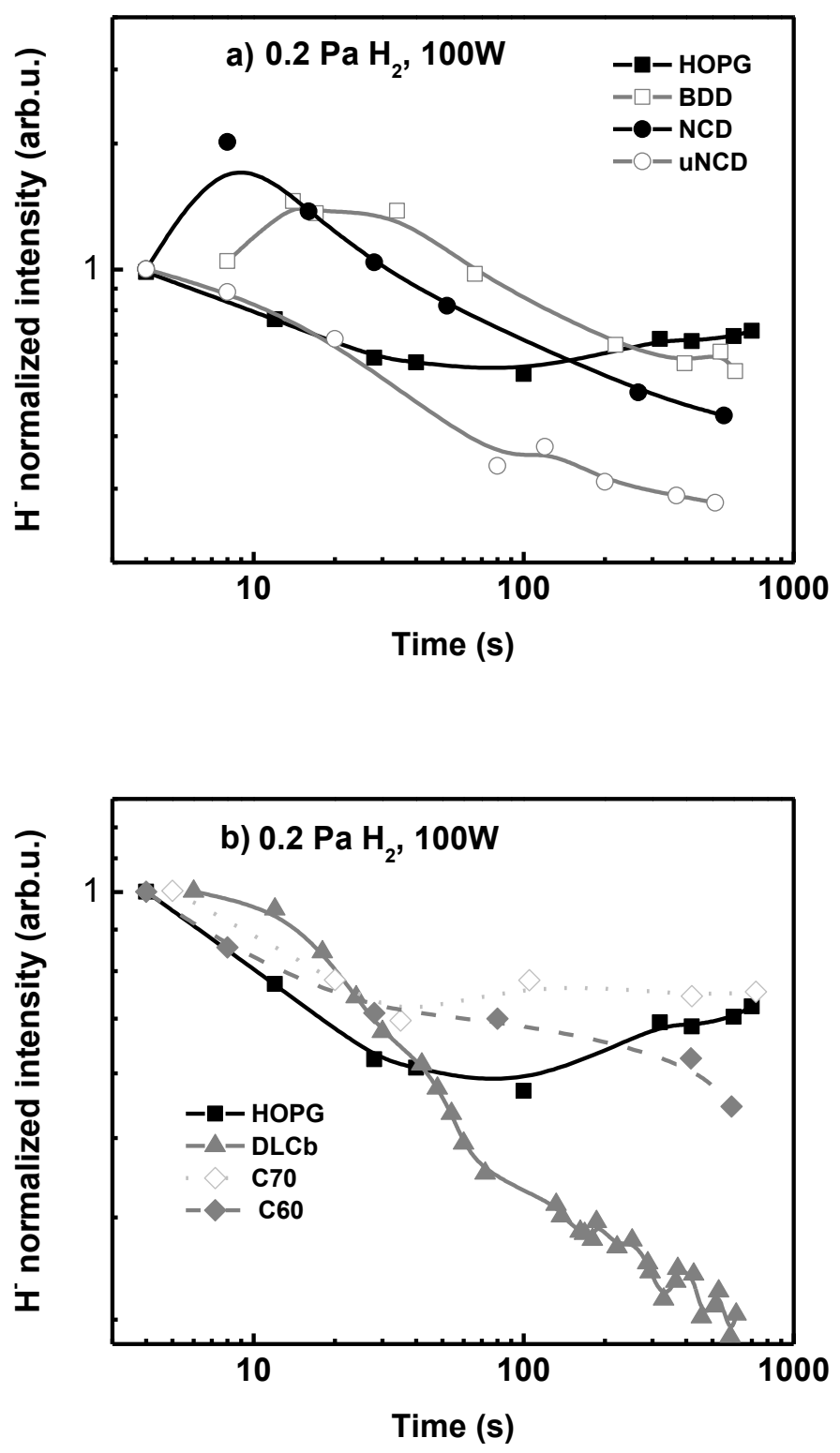

Figure 2: Temporal evolution of $\mathrm{H}$ - intensity for different materials at $0.2 \mathrm{~Pa} \mathrm{H}_{2}$ and $100 \mathrm{~W}$.

For all materials, the first measurement after $\mathrm{t}=0$ has been normalized to 1 . 

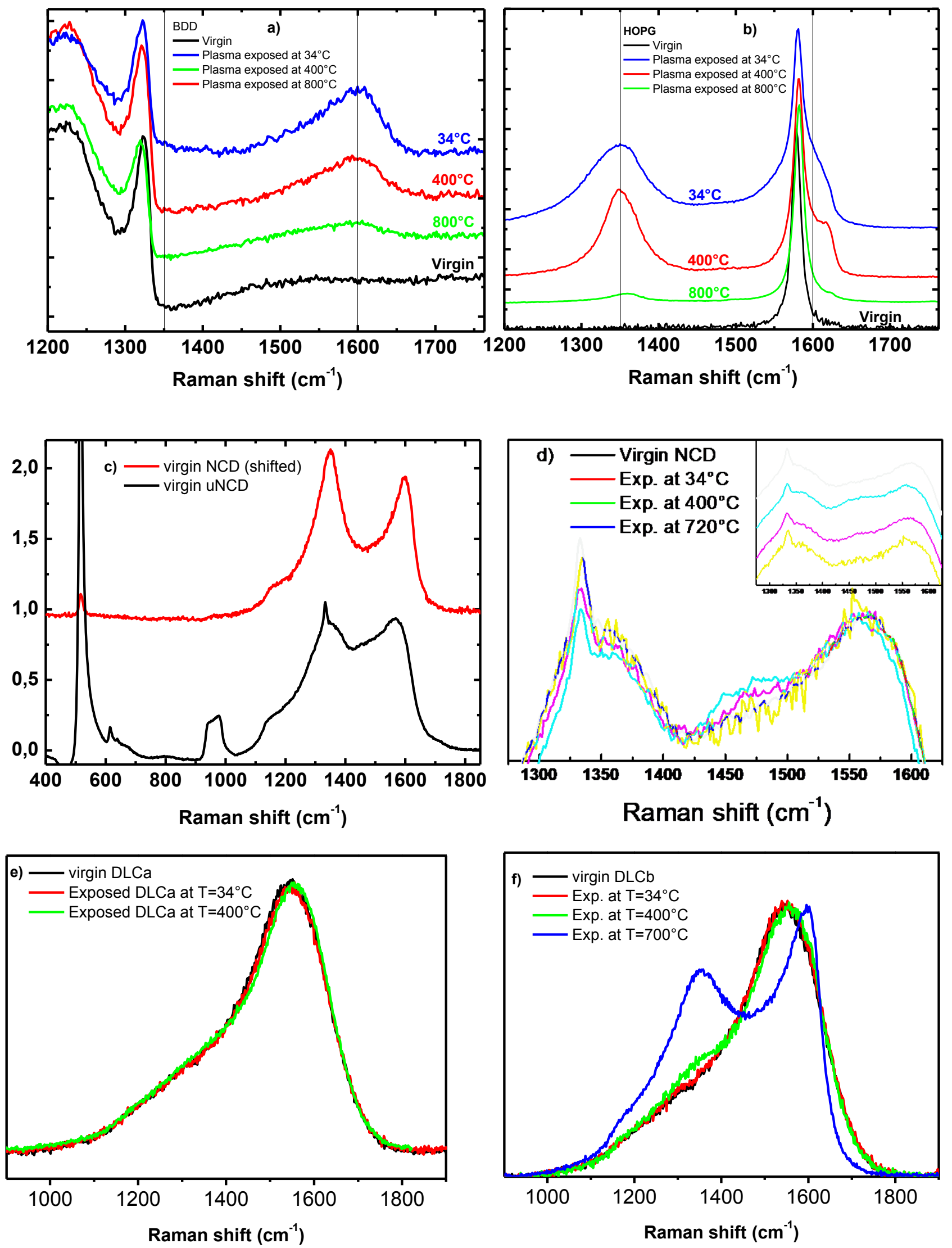
Figure 3: left to right, top to bottom a) Raman spectra of pristine and plasma exposed BDD sample at three different surface temperatures b) Raman spectra of pristine and plasma exposed HOPG sample at three different surface temperatures c) Raman spectra of pristine NCD, uNCD d) Comparison between Raman spectra of pristine and plasma exposed NCD sample at three different temperatures e) Comparison between Raman spectra of pristine and plasma exposed DLCa f) Comparison between Raman spectra of pristine and plasma exposed DLCb at three different temperatures 

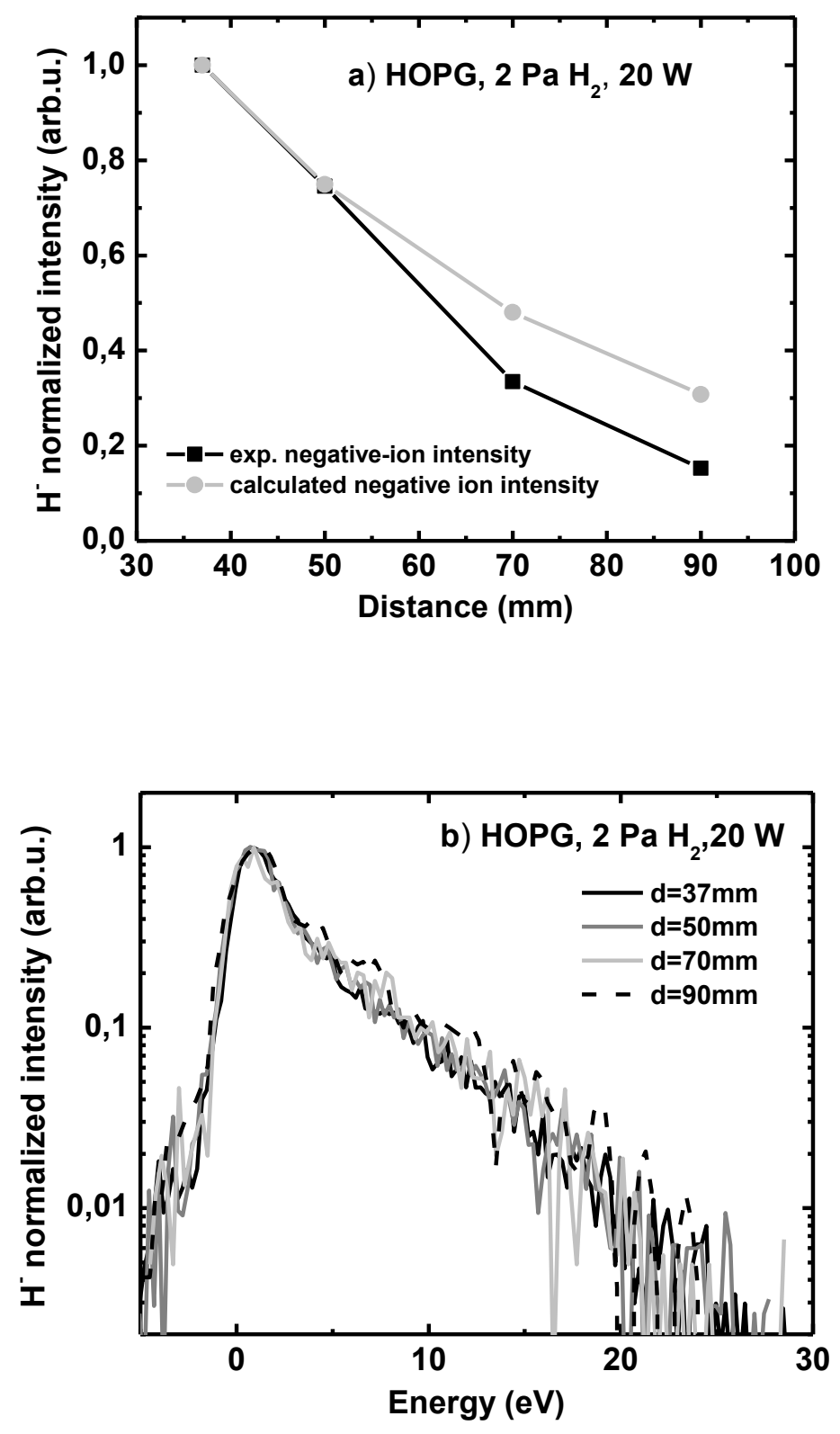

Figure 4: a) Experimental decrease of negative-ion intensity with sample to mass spectrometer distance (black) and calculated decrease of negative-ion intensity due to detachment collisions of $\mathrm{H}$ with $\mathrm{H} 2$ molecules (grey) (HOPG surface, $2 \mathrm{~Pa}, 20 \mathrm{~W}$ ). Intensities have been normalized to 1 at 37 $\mathrm{mm}$ distance b) Normalized negative-ion energy distribution functions at different sample to mass spectrometer distances (HOPG surface, $2 \mathrm{~Pa}, 20 \mathrm{~W}$ ) 

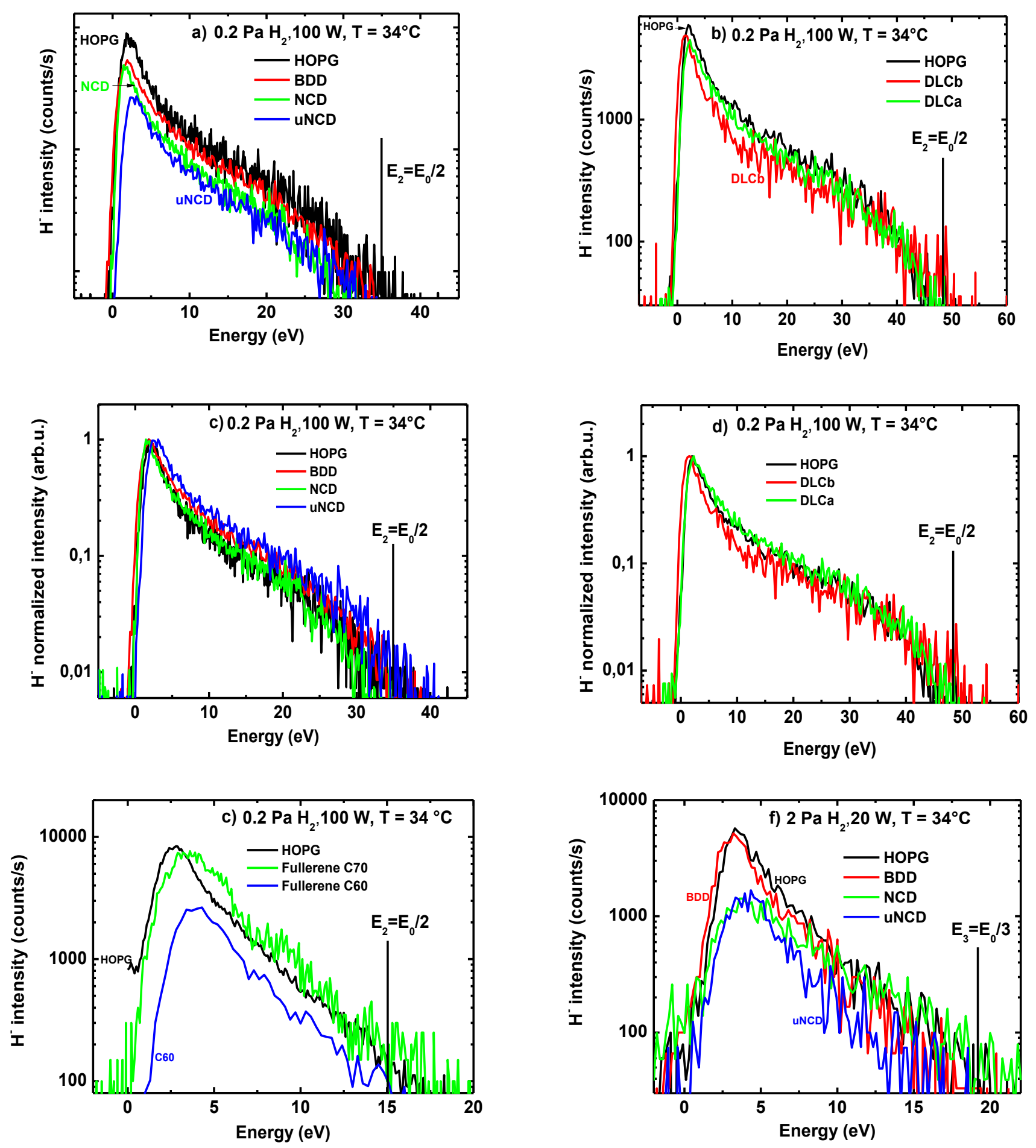

Figure 5: Negative-ion energy distribution functions measured on different materials a) HOPG, BDD, NCD and uNCD at plasma condition $\left.1\left(0.2 \mathrm{~Pa}, 100 \mathrm{~W}, \mathrm{E}_{0}=70 \mathrm{eV}\right) \mathrm{b}\right) \mathrm{HOPG}$, DLC-a, and DLC-b at 
plasma condition $\left.1\left(0.2 \mathrm{~Pa}, 100 \mathrm{~W}, \mathrm{E}_{0}=110 \mathrm{eV}\right) \mathrm{c}\right) \mathrm{HOPG}, \mathrm{BDD}, \mathrm{NCD}$ and $\mathrm{uNCD}$ at plasma condition $1\left(0.2 \mathrm{~Pa}, 100 \mathrm{~W}, \mathrm{E}_{0}=70 \mathrm{eV}\right)$, NIDF normalized to $\left.1 \mathrm{~d}\right) \mathrm{HOPG}$, DLC-a, and DLC-b at plasma condition $1\left(0.2 \mathrm{~Pa}, 100 \mathrm{~W}, \mathrm{E}_{0}=110 \mathrm{eV}\right)$, NIDF normalized to $\left.1 \mathrm{e}\right) \mathrm{HOPG}, \mathrm{C} 70, \mathrm{C} 60$ at plasma condition 1 without screen $\left.\left(0.2 \mathrm{~Pa}, 100 \mathrm{~W}, \mathrm{E}_{0}=25 \mathrm{eV}\right) \mathrm{f}\right) \mathrm{HOPG}, \mathrm{BDD}, \mathrm{NCD}$ and $\mathrm{uNCD}$ at plasma condition $2\left(2 \mathrm{~Pa}, 20 \mathrm{~W}, \mathrm{E}_{0}=60 \mathrm{eV}\right)$. $\mathrm{E}_{0}$ is the positive ion impact energy. 

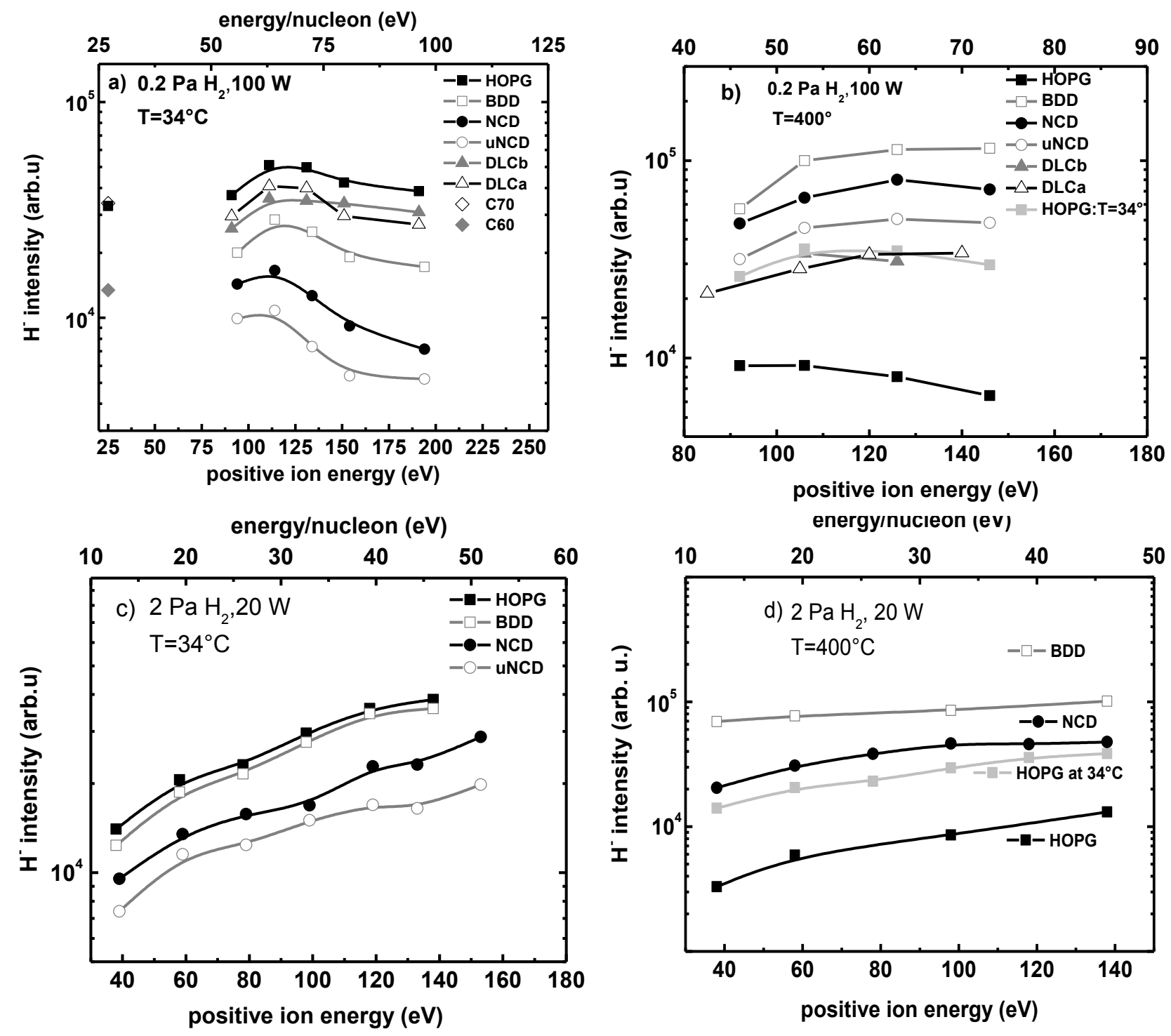

Figure 6: negative-ion yields on different carbon surfaces versus positive-ion energy a) at room temperature and plasma condition $1(0.2 \mathrm{~Pa}), \mathrm{b})$ at high temperature $\left(400^{\circ} \mathrm{C}\right)$ and plasma condition 1 $(0.2 \mathrm{~Pa}) \mathrm{c})$ at room temperature and plasma condition $2(2 \mathrm{~Pa}) \mathrm{d})$ at high temperature $\left(400^{\circ} \mathrm{C}\right)$ and plasma condition 2 (2 Pa). C70 and C60 materials have been exposed at plasma condition $1(0.2 \mathrm{~Pa})$ without screen (see text). HOPG exposed in the same condition is also presented on the figure. 

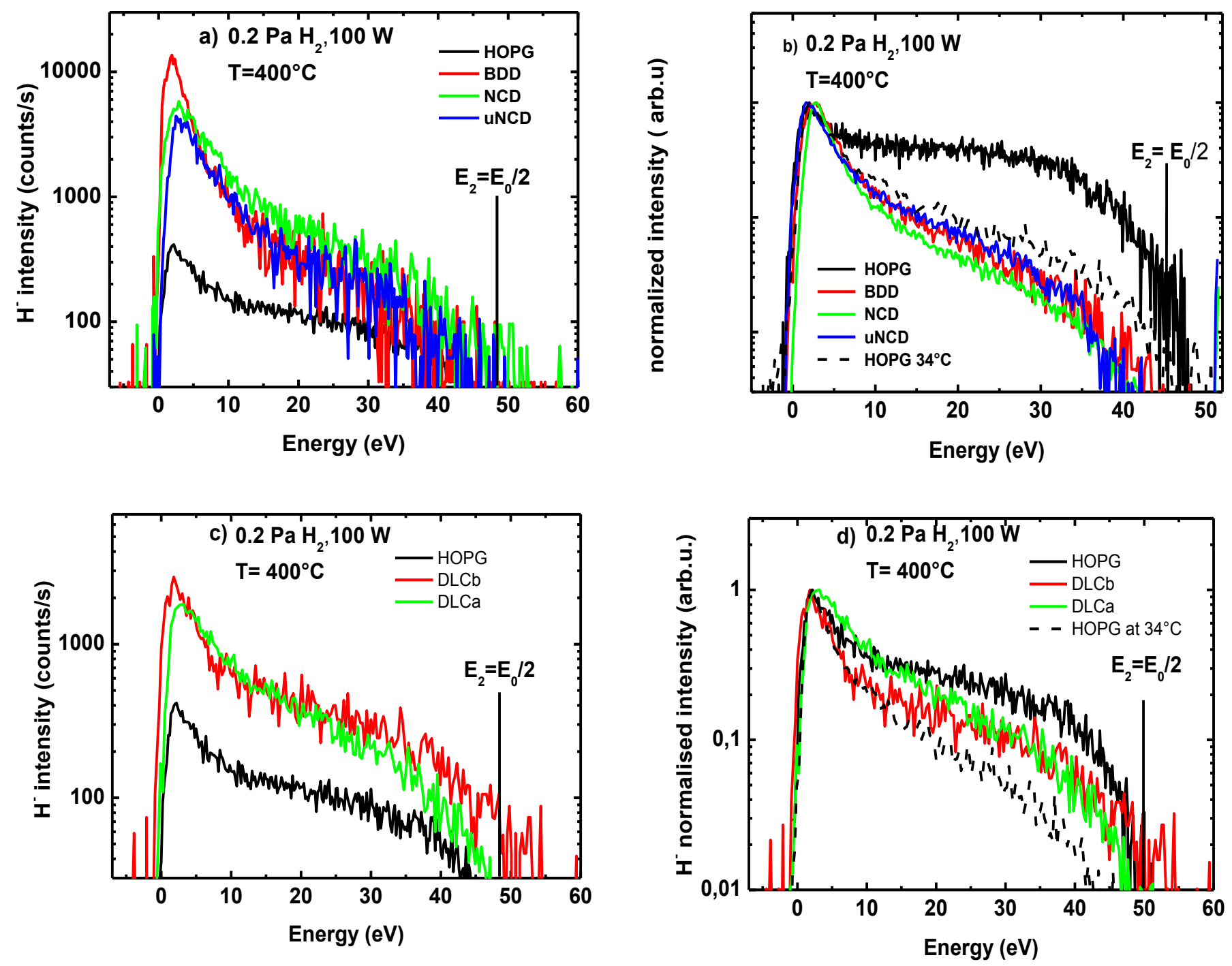

Figure 7: Negative-ion energy distribution functions (non-normalized on left, normalized on right) measured at plasma condition $1(0.2 \mathrm{~Pa})$, for $\mathrm{E}_{0}=100 \mathrm{eV}$ (positive ion impact energy), for a surface temperature of $400^{\circ} \mathrm{C}$ using $\mathrm{HOPG}, \mathrm{BDD}, \mathrm{NCD}$, uNCD materials (top) and $\mathrm{HOPG}$, DLC-b, and $\mu \mathrm{CD}$ materials (bottom). 


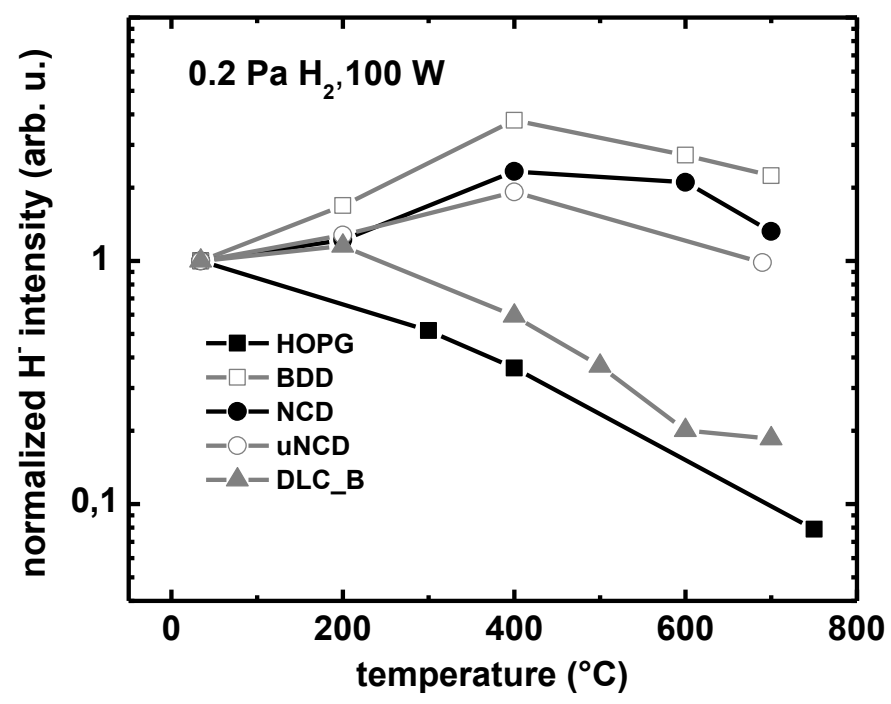

Figure 8: Negative-ion yields on different carbon surfaces versus temperature at plasma condition $1(0.2 \mathrm{~Pa}, 100 \mathrm{~W})$ and positive ion energy $\mathrm{E}_{0}=100 \mathrm{eV}(\mathrm{Vs}=-80 \mathrm{~V})$. All yields have been normalized to 1 at room temperature. 


\section{References:}

${ }^{1}$ D Kanjilal, S. Chopra, M M Narayanan, Indira S Iyer, VandanaJha, R. Joshi and S K Datta, Nuclear Instruments and Methods in Physics Research A 328 (1993) 97-100

${ }^{2}$ Minoru Yoned, Yasuyuki Shibata, Atsushi Tanaka, Takashi Uehiro, Masatoshi Morita, Masao Uchida, Toshiyuki Kobayashi, Chiaki Kobayashi, Ryo Suzuki, Keisuke Miyamoto, Boze Hancock, Chris Dibden and John S. Edmonds, Nuclear Instruments and Methods in Physics Research B 223-224 (2004) 116-123

${ }^{3}$ A. Aanesland, A. Meige, and P. Chabert, J. Phys.: Conf. Ser. 162, 012009 (2009)

${ }^{4}$ L. Popelier, A. Aanesland, and P. Chabert, J. Phys. D: Appl. Phys. 44, 315203 (2011)

5 Samukawa S, Sakamoto K and Ichiki K 2001 "High-efficiency low energy neutral beam generation using negative ions in pulsed plasma" Japan. J. Appl.Phys. Part 240 L997-9

${ }^{6}$ Draghici M and Stamate E 2010 "Properties and etching rates of negative ions in inductively coupled plasmas and dc discharges produced in Ar/SF6" J. Appl. Phys. 107123304

${ }^{7}$ Vozniy O V and Yeom G Y "High-energy negative ion beam obtained from pulsed inductively coupled plasma for charge-free etching process Appl. Phys. Lett. 94231502 (2009)

${ }^{8}$ E. Stamate and M. Draghici, "High electronegativity multi-dipolar electron cyclotron resonance plasma source for etching by negative ions", J. Appl. Phys. 111, 083303 (2012)

${ }^{9}$ O. V. Vozniy and G. Y. Yeom "High-energy negative ion beam obtained from pulsed inductively coupled plasma for charge-free etching process" Appl. Phys. Lett. 94, 231502 (2009)

10 Toshikazu Shibayama, Haruo Shindo and Yasuhiro Horiike, Plasma Sources Sci. Technol. 5 (1996) 254

${ }^{11}$ Seiji Samukawa and Tetsu Mieno, Plasma Sources Sci. Technol. 5 (1996) 132

${ }^{12}$ Hiroto Ohtake and Seiji Samukawa, Appl. Phys. Lett. 68, (1996) 2416

13 Y. Shimomura, R. Aymar, V. Chuyanov, M. Huguet, R. Parker and ITER Joint Central Team, Nucl. Fusion 39 (1999) 1295

${ }^{14}$ R. Aymar. Fusion Engineering and Design, 55 (2001) 107

${ }^{15}$ R. Aymar, P. Barabaschi and Y. Shimomura. Plasma Phys. Control Fusion 44 (2002) 519

${ }^{16}$ T. Inoue, E. Di Pietro, M. Hanada, R. S. Hemsworth, A. Krylov, V. Kulygin, P. Massmann, P. L. Mondino, Y. Okumura, A. Panasenkov, E. Speth and K. Watanabe, Fusion Engineering and Design, 56-57, (2001) 517

${ }^{17}$ U Fantz, P Franzen, W Kraus, M Berger, S Christ-Koch, M Fröschle, R Gutser, B Heinemann, C Martens, P McNeely, R Riedl, E Speth and D Wünderlich, Plasma Phys. Control. Fusion 49 (2007) B 563

${ }^{18}$ V Dudnikov, "Forty years of surface plasma source development" Rev. Sci. Instrum. 83, 02A708 (2012)

${ }^{19}$ Handbook of ion sources, Edited by Bernhard Wolf, CRC Press (1995)

${ }^{20}$ M. Bacal, "Physics Aspects of Negative Ion Sources," Nuclear Fusion 46 (2006): S250.

${ }^{21}$ Bechu S, Lemoine D, Bacal M, Bes A and Pelletier J 2009 AIP Conf. Proc. 1097 74-83

${ }^{22}$ E I Toader, V N Covlea andW G Graham, "The electronegative character of a reflex discharge source operating in hydrogen", Plasma Sources Sci. Technol. 15 (2006) 288-293

23 Ts. Paunska, A. Shivarova, and Kh. Tarnev, "A small radius hydrogen discharge: An effective source of volume produced negative ions", J. Appl. Phys. 107, 083301 (2010)

${ }^{24}$ R Middleton, Nuclear Instruments and Methods, 144 (1977) 373

25 T. Kalvas, O. Tarvainen, J. Komppula, M. Laitinen, T. Sajavaara, H. Koivisto, A. Jokinen, and M. P. Dehnel, "Recent negative ion source activity at JYFL", AIP Conf. Proc. 1515, pp. 349-358

${ }^{26}$ R Middleton, Nuclear Instruments and Methods in Physics Research, 214 (1983) 139

${ }^{27}$ L. Schiesko, P. McNeely, U. Fantz, P. Franzen, and NNBI Team, Plasma, Phys. Controlled Fusion 53, 085029 (2011)

${ }^{28}$ P. Franzen, L. Schiesko, M. Froschle, D. Wünderlich, U. Fantz, and the NNBI Team, Plasma Phys. Controlled Fusion 53, $115006(2011)$

${ }^{29}$ Yasuhiko Takeiri "Negative ion source development for fusion application”, Rev. Sci. Instrum. 81, 02B114 (2010)

${ }^{30} \mathrm{~S}$ Pestchanyi,VSafronov,ILandman, Journal of Nuclear materials, 329-333 Part1 (2004) 697 
${ }^{31}$ H Bolt, V Barabash,W Krauss,J Linke,R Neu,S Suzuki, N Yoshida, ASDEX Upgrade Team, Journal of Nuclear materials, 329-333 Part1 (2004) 66

${ }^{32}$ M. van den Berg, S. Brons, O.G. Kruijt, J. Scholten, R. Pasquet, P.H.M. Smeets, B. Schweer, and G. De Temmerman, "The target for the new plasma/wall experiment Magnum-PSI", Fus. Eng. Des., 86 (2011) 1745

${ }^{33}$ G De Temmerman et al., "Interactions of Diamond Surfaces with Fusion Relevant Plasmas," Physica Scripta T138 (December 2009): 014013, doi:10.1088/0031-8949/2009/T138/014013.

${ }^{34}$ Samuele Porro et al., "Nanocrystalline Diamond Coating of Fusion Plasma Facing Components," Diamond and Related Materials 18, no. 5-8 (May 2009): 740-744, doi:10.1016/j.diamond.2009.01.006.

35 G. De Temmerman et al., "Thermal Shock Resistance of Thick Boron-doped Diamond Under Extreme Heat Loads," Nuclear Fusion 51, no. 5 (2011): 052001.

${ }^{36}$ Mathew C. Guenette et al., "NEXAFS Spectroscopy of CVD Diamond Films Exposed to Fusion Relevant Hydrogen Plasma," Diamond and Related Materials 34 (2013) 45-49.

${ }^{37}$ Boyd D Blackwell et al., "Design and Characterization of the Magnetized Plasma Interaction Experiment (MAGPIE): a New Source for Plasma-material Interaction Studies," Plasma Sources Science and Technology 21, no. 5 (October 1, 2012): 055033, doi:10.1088/0963-0252/21/5/055033.

38 C. M. Samuell et al., "Plasma Parameters and Electron Energy Distribution Functions in a Magnetically Focused Plasma," Physics of Plasmas 20, no. 3 (2013): 034502, doi:10.1063/1.4794841.

${ }^{39}$ B. de Groot, R.S. Al, R. Engeln, W.J. Goedheer, O.G. Kruijt, H.J.v.d. Meiden, P.R. Prins, D.C. Schram, P.H.M. Smeets, V.P. Veremiyenko, W.A.J. Vijvers, J. Westerhout, A.W. Kleyn, N.J. Lopes Cardozo, G.J. van Rooij, "Extreme hydrogen plasma fluxes at Pilot-PSI enter the ITER divertor regime”, Fusion Engineering and Design 82 (2007) 1861-1865

${ }^{40}$ S.I. Krasheninnikov,A.Yu. Pigarov,T.K. Soboleva,D.J. Sigmar, Journal of Nuclear materials, $241-243$ (1997) 283

${ }^{41}$ L. Schiesko et al., "Negative Ion Surface Production through Sputtering in Hydrogen Plasma," Applied Physics Letters 95, no. 19 (2009): 191502, doi:10.1063/1.3258352.

${ }^{42}$ L. Schiesko et al., "H- Production on a Graphite Surface in a Hydrogen Plasma," Plasma Sources Science and Technology 17 (2008): 035023.

${ }^{43}$ L. Schiesko et al., "A Comparative Study of H- and D- Production on Graphite Surfaces in H2 and D2 Plasmas," Plasma Sources Science and Technology 19 (2010): 045016.

${ }^{44}$ P. Kumar et al., "Enhanced Negative Ion Yields on Diamond Surfaces at Elevated Temperatures," Journal of Physics D: Applied Physics 44 (2011): 372002.

45 JA Scheer et al., "High Negative Ion Yield from Light Molecule Scattering," Nuclear Instruments and Methods in Physics Research Section B: Beam Interactions with Materials and Atoms 230, no. 1 (2005): 330-339.

${ }^{46}$ Patrick P. Hughes, Michael A. Coplan, Jeffery N. DeFazio, Dennis J. Chornay, Michael R. Collier, Keith W. Ogilvie, and Mark D. Shappirio "Scattering of neutral hydrogen at energies less than 1 keV from tungsten and diamondlike carbon surfaces” J. Vac. Sci. Technol. A 27 (2009) 1188

${ }^{47}$ P. Wurz, R. Schletti, M.R. Aellig "Hydrogen and oxygen negative ion production by surface ionization using diamond surfaces” Surface Science 373 (1997) 56-66

${ }^{48}$ M.A. Gleeson, A.W. Kleyn, Nuclear Instruments and Methods in Physics Research B 157 (1999) 48-54

49 J. Lienemann et al., "Negative Ion Formation During Scattering of Fast Ions from Diamond-like Carbon Surfaces," Nuclear Instruments and Methods in Physics Research Section B: Beam Interactions with Materials and Atoms 269 , no. 9 (2011): 915-918.

${ }^{50}$ F. Bonetto et al., "Experimental and Theoretical Study of Charge Transfer in Hydrogen Ion Scattering from a Graphite Surface," Applied Surface Science 254, no. 1 (2007): 62-64.

51 RA Vidal et al., "Electron Capture and Loss in the Scattering of $\mathrm{H}<\mathrm{Sup}>+</$ sup $>$ from HOPG Graphite," Surface Science 605, no. 1 (2011): 18-23.

52 A. Ahmad et al., "Negative-ion Surface Production in Hydrogen Plasmas: Modeling of Negative-ion Energy Distribution Functions and Comparison with Experiments," Plasma Sources Science and Technology 22, no. 2 (2013): 025006.

${ }^{53}$ F. Silva, K. Hassouni, X. Bonnin and A. Gicquel, Journal of Physics: Condensed Matter, 21, 364202 (2009).

${ }^{54}$ Jarry, O., Jaoul, C., Tristant, P., Merle-Méjean, T., Colas, M., Dublanche-Tixier, C., Ageorges, H., Lory, C., Jacquet, J.-M., "Tribological behaviour of diamond-like carbon films used in automotive application: A comparison", Plasma Processes and Polymers, vol. 6, no. SUPPL. 1, (2009) pp. S478-S482

${ }^{55}$ Robertson J., Mechanisms of sp3 bond formation in the growth of diamond-like carbon, Diamond and Related Materials, 2005, vol. 14, p. 942-948

56 G. Cartry et al., "Production of Negative Ions on Graphite Surface in H2/D2 Plasmas: Experiments and Srim Calculations," Physics of Plasmas 19, no. 6 (2012): 063503, doi:10.1063/1.4725188 
${ }^{57}$ C. Pardanaud, A. Ahmad, G. Cartry, C. Martin, L. Schiesko, G. Giacometti, M. Carrere and P. Roubin, Raman microscopy and AFM analysis of graphite H, D and He bombarded perpendicularly and parallel to the basal planes: observation of nanometric domes produced by amorphisation, to be submitted

${ }^{58}$ Lucchese, M. M., F. Stavale, et al. (2010). "Quantifying ion-induced defects and Raman relaxation length in graphene."Carbon48(5): 1592-1597.

${ }^{99}$ Tuinstra, F. and J. L. Koenig (1970)."Raman spectrum of graphite." J. Chem. Phys.53(3): 1126.

${ }^{60}$ F. Pruvost, E. Bustarret, A. Deneuville, "Characteristics of homoepitaxial heavily boron-doped diamond films from their Raman spectra", Diamond and Related Materials 9 (2000) 295-299

${ }^{61}$ F. Pruvost and A. Deneuville, "Analysis of the Fano in diamond" Diamond and Related Materials 10 (3-7): 531-535

${ }^{62}$ Ferrari, A. C. and J. Robertson (2001)."Origin of the $1150 \mathrm{~cm}-1$ Raman mode in nanocrystalline diamond."Phys. Rev. B63: 121405.

${ }^{63}$ Ferrari, A. C. and J. Robertson (2001)."Resonant Raman spectroscopy of disordered, amorphous, and diamondlike carbon."Phys. Rev. B64(7): 075414.

${ }^{64}$ Piscanec, S., F. Mauri, et al. (2005). "Ab initio Raman spectra of diamond like carbons." Diamond relat.mater.14: 1078.

${ }^{65}$ R. Brunetto, G. A. Baratta, and G. Strazzulla, "Raman Spectroscopy of Ion Irradiated Diamond," Journal of Applied Physics 96, no. 1 (2004): 380, doi:10.1063/1.1759080.

${ }^{66}$ Huang-Chin Chen, Umesh Palnitkar, Balakrishnan Sundaravel, I-Nan Lin, Abhinav Pratap Singh, Ravi Kumar Ranade, "Enhancement of field emission properties in nanocrystalline diamond films upon $100 \mathrm{MeV}$ silver ion irradiation", Diamond \& Related Materials 18 (2009) 164-168

${ }^{67} \mathrm{~J}$. Robertson, "Recombination and photoluminescence mechanism in hydrogenated amorphous carbon" Phys. Rev. B 53, $16302(1996)$

${ }^{68}$ C. Casiraghi, A. C. Ferrari,and J. Robertson, "Raman spectroscopy of hydrogenated amorphous carbons", Phys. Rev. B 72, 085401 (2005)

${ }^{69}$ C. Pardanaud, C. Martin, P. Roubin, G. Giacometti , C. Hopf, T. Schwarz-Selinger , W. Jacob, "Raman spectroscopy investigation of the H content of heated hard amorphous carbon layers", Diamond and related materials 34 (2013) 100104

${ }^{70}$ Eklund et al. Thin solid films 257 (1995) 185

${ }^{71}$ Rao et al. Chem. Phys. Lett. 224 (1994) 106

${ }^{72}$ Phelps A V 1990 J. Phys. Chem. Ref. Data 19653

${ }^{73}$ Ferrari, A. C. and J. Robertson (2000)."Interpretation of Raman spectra of disordered and amorphous carbon."Phys. Rev. B61(20): 14095.

${ }^{74}$ I. Villalpando, P. John, S. Porro, J.I.B. Wilson, Hydrogen plasma etching of diamond films deposited on graphite, Diamond \& Related Materials 20 (2011) 711-716

${ }^{75}$ L. Diederich et al., "Electron Affinity and Work Function of Differently Oriented and Doped Diamond Surfaces Determined by Photoelectron Spectroscopy," Surface Science 418, no. 1 (1998): 219-239.

${ }^{76}$ J. Van der Weide et al., "Negative-electron-affinity Effects on the Diamond (100) Surface," Physical Review B 50, no. 8 (1994): 5803.

${ }^{77}$ F. J. Himpsel et al., "Quantum Photoyield of Diamond (111) —A Stable Negative-affinity Emitter," Physical Review B 20, no. 2 (1979): 624.

${ }^{78}$ AG Borisov and V. Sidis, "Theory of Negative-ion Conversion of Neutral Atoms in Grazing Scattering from Alkali Halide Surfaces," Physical Review B 56, no. 16 (1997): 10628.

${ }^{79}$ A. V. Karabutov, V. D. Frolov, and V. I. Konov, "Diamond/sp $<$ Sup $>2</$ sup $>$-bonded Carbon Structures: Quantum Well Field Electron Emission?," Diamond and Related Materials 10, no. 3 (2001): 840-846.

${ }^{80}$ Nan Jiang et al., "Structural Characteristics and Field Electron Emission Properties of Nano-diamond/carbon Films," Journal of Crystal Growth 236, no. 4 (2002): 577-582.

${ }^{81}$ J. Mauricio Rosolen et al., "Electron Field Emission from Composite Electrodes of Carbon Nanotubes-boron-doped Diamond and Carbon Felts," Applied Physics Letters 88, no. 8 (2006): 083116-083116.

${ }^{82}$ Dongsung Hong and Dean M. Aslam, Technology and Characterization of Diamond Field Emitter Structures, IEEE TRANSACTIONS ON ELECTRON DEVICES 45-4 (1998) 977

${ }^{83}$ J.A. Scheer, M. Wieser, P. Wurz, P. Bochsler, E. Hertzberg, S.A. Fuselier, F.A. Koeck, R.J. Nemanich, M. Schleberger, High negative ion yield from light molecule scattering, Nuclear Instruments and Methods in Physics Research B 230 (2005) 330-339

${ }^{84}$ E D de Rooij, "Molecular Dynamics Simulations of Interactions Between Hydrogen and Fusion-relevant Materials" (PhD thesis, Utrecht University, 2010).

${ }^{85}$ Y. Yamazaki, K. Ishikawa, N. Mizuochi, S. Yamasaki, Structural change in diamond by hydrogen plasma treatment at room temperature, Diamond \& Related Materials 14 (2005) 193961942 
${ }^{86}$ Y. Yamazaki, K. Ishikawa, N. Mizuochi, S. Yamasaki, Structure of diamond surface defective layer damaged by hydrogen ion beam exposure, Diamond \& Related Materials 15 (2006) 703-706

${ }^{87}$ W. Jacob and W. Moller, "On the Structure of Thin Hydrocarbon Films," Applied Physics Letters 63, no. 13 (1993): $1771-1773$.

${ }^{88}$ J. Robertson, "Diamond-like Amorphous Carbon," Materials Science and Engineering: R: Reports 37, no. 4 (2002): $129-281$. 